\title{
Antimicrobial compounds were isolated from the secondary metabolites of endophytic Gordonia in the intestinal tract of Periplaneta americana
}

\section{Yan Ma}

Guangdong Pharmaceutical University

\section{Minhua Xu}

Guangdong Pharmaceutical University

Hancong Liu

Guangdong Pharmaceutical University

Tiantian Yu

Guangdong Pharmaceutical University

\section{Ping Guo}

Guangdong Pharmaceutical University

Wenbin Liu

Guangdong Pharmaceutical University

Xiaobao Jin ( $\nabla$ jinxf2001@163.com )

Guangdong Pharmaceutical University

\section{Research Article}

Keywords: Endophytic Gordonia, Secondary metabolites, Antimicrobial activity, Cytotoxicity, Periplaneta americana

Posted Date: March 22nd, 2021

DOI: https://doi.org/10.21203/rs.3.rs-313547/v1

License: (c) (1) This work is licensed under a Creative Commons Attribution 4.0 International License. Read Full License 


\section{Antimicrobial compounds were isolated from the secondary metabolites of endophytic Gordonia in the intestinal tract of \\ Periplaneta americana}

Yan $\mathrm{Ma}^{1,2}$ \# Minhua $\mathrm{Xu}^{1,2}$ \# Hancong Liu ${ }^{1,2}$ Tiantian $\mathrm{Yu}^{1,2}$ Ping Guo ${ }^{1,2}$ Wenbin Liu ${ }^{1,2}$ and Xiaobao $\operatorname{Jin}^{1,2} *$

1 School of Life Sciences and Biopharmaceutics, Guangdong Pharmaceutical University, Guangzhou, 510006, China,

2 Guangdong Provincial Key Laboratory of Pharmaceutical Bioactive Substances, Guangdong

Pharmaceutical University, Guangzhou, 510006, China

\# These authors contributed equally to this work.

* Correspondence to: Xiaobao Jin. E-mail: jinxf2001@163.com

\section{Abstract}

Background: As we all know, bacterial and fungal infections have become one of the threats to human health. Microbial secondary metabolites are one of the main sources of bioactive natural products. It is estimated that around $60 \%$ of all foregone antibiotics are derived from secondary metabolites produced by filamentous actinomycete bacteria. Gordonia spp. are members of the actinomycete family, their contribution to the environment improvement and environmental protection by their biological degradation ability, but there are few studies on their antimicrobial activity of their secondary metabolites. Our team isolated a Gordonia strain WA 4-31 with anti-Candida albicans activity from the intestinal tract of Periplaneta americana in the early stage.

Results: In this study, we firstly identified the strain WA 4-31 by the morphological characteristics and the phylogenetic analyses, and found that it homologous to a strain of Gordonia from the Indian desert (EU333873) by 100\%. Then four compounds, Actinomycin D (1), Actinomycin $\mathrm{X}_{2}(2)$, Mojavensin A (3) and cyclic (leucine-leucne) dipeptide (4) were purified from the EtOH extract of the fermented broth of the strain. The compounds 1-4 had activities against Candida albicans, Aspergillus niger, 
Aspergillus fumigatus and Trichophyton rubrum. They also had activities against MRSA, S.aureus, K.peneumoniae and E.coli in different degree. The minimum inhibitory concentration of Actinomycin D and Actinomycin $\mathrm{X}_{2}$ on MASA was $0.25 \mu \mathrm{g} / \mathrm{mL}$. Interestingly, we found that when Mojavensin A was mixed with compound 4 ratio of $1: 1$, the solution of the compounds was better than the single on anti-Candida albicans. Besides, compounds 1-3 had varying degrees of cytotoxicity on CNE-2 cells and HepG-2 cells.

Conclusions: The present study firstly reported the antimicrobial compounds isolated from Gordonia.

These indicated that rare actinomycetes from the intestinal tract of Periplaneta americana possessed a potential as a source of active secondary metabolites.

Keywords: Endophytic Gordonia ; Secondary metabolites; Antimicrobial activity; Cytotoxicity; Periplaneta americana;

\section{Introduction}

Microbial secondary metabolites are one of the main sources of bioactive natural products and are also one of the main sources of drugs. It is estimated that around $60 \%$ of all foregone antibiotics are derived from secondary metabolites produced by filamentous actinomycete bacteria, especiely Streptomyces species. But over time, the continual rediscovery of known compounds from secondary metabolites of Actinomyces has resulted. Consequently, special extreme environment and growing conditions for bacteria raised much concerns in recent years[1], such as deep-sea environment, with characteristic features of high salinity, high pressure, low temperature and low nutrition [2, 3]; cold polar regions [4]; deserts [5, 6] or endogenous environment in insects and plants[7, 8]. 
Endophytic microorganisms of insects and plants have attracted much attention in recent years.

They play important role of acting as reservoirs of novel bioactive secondary metabolites that serve as a potential candidate for antimicrobial, anti-insect, anticancer and many more properties [9]. In order to cope with the emergence of drug resistance, scientific efforts have been aimed at the bioprospecting of microorganisms' secondary metabolites, with special emphasis on the search for antimicrobial natural products derived from endophytes[10-12]. Silva et al. isolated and identified endophytic fungal communities from the roots and seeds of $P$. cupana genotypes susceptible and tolerant to anthracnose that grow in two sites of the Brazilian Amazonia forest. They also identified eight fungal species not previously reported as endophytes; some fungal species capable of inhibiting pathogen growth; and the production of antibiotics and compounds with bacteriostatic activity against Pseudomonas aeruginosa in both susceptible and multiresistant host strains[13].

Besides, in the existing research reports of insect endophytes, most of them focus on pest control, biological agents, ecological protection and ecological diversity, and the study on antibacterial activity of their secondary metabolites is less[14-17]. Our previous study showed that the endophytic strains in the intestinal tract of Periplaneta americana had various antibacterial activities against pathogenic bacteria. Fang et al. found one actinomycete strain WA23-4-4 isolated from the intestinal tract of Periplaneta americana that exhibited broad spectrum antifungal activity. 3-Acetyl benzoyl amide was isolated by ethyl acetate extraction of WA23-4-4 fermentation broth, and the compound showed significant activity against Candida albicans and Aspergillus niger[18]. Chen et al. also found one strain WA5-2-37 isolated from the intestinal tract of Periplaneta americana, exhibited great activity against MRSA[19]. The strain produced actinomycin $X_{2}$ and collismycin A had strong inhibition for MRSA with minimum inhibitory concentration (MIC) values of 0.25 and $8 \mu \mathrm{g} / \mathrm{mL}$. 
Rare actinomycetes have been paid more attention as the hope of discovering new antibiotics. At present, some antibiotics that have been used in clinic, such as gentamicin, erythromycin, vancomycin and rifampicin, are all from rare actinomycetes[20]. Rare actinomycete Gordonia are usually used for the environment improvement and environmental protection by its biological degradation ability, but there are few studies on its antimicrobial activity[21]. Our team isolated a Gordonia strain WA 4-31 with anti-Candida albicans activity from the intestinal tract of Periplaneta americana. In this study, four compounds were isolated and purified from the ethyl acetate extract of fermentation broth of the Gordonia strain WA 4-31 with antimicrobial activity, especially compounds1-3 Actinomycin D (1), Actinomycin $\mathrm{X}_{2}$ (2), Mojavensin A (3) showed better anti-fungal and anti-cancer activities. The study firstly reported the antimicrobial compounds isolated from Gordonia from the intestinal tract of Periplaneta americana. These indicated that Gordonia rare actinomycetes possessed a great potential as a source of active secondary metabolites.

\section{Results}

\section{Identification of the strain WA 4-31}

The colonies of strain WA 4-31 on Gauze's medium were milky yellow. The surface of the colony was smooth and moist, and its edge was irregularly convex (Fig. 1 (A)). The strain WA 4-31 was observed to be short rod-shaped and unbranched under electron microscope (Fig. 1 (B) (C)). The sequence of this strain WA 4-31 was submitted to GenBank of NCBI, and the accession number was MH613773. The strain WA 4-31 of the 16S rRNA gene sequence was compared by BLAST and homologous to a strain of Gordonia from the Indian desert (EU333873) by 100\% (Fig. 1 (E)).

\section{Isolation of Secondary Metabolites}


The crude ethyl acetate extract (about $13.4 \mathrm{~g}$ ) was firstly separated by silica gel column chromatography eluting with a gradient system of $\mathrm{CHCl}_{3}: \mathrm{CH}_{3} \mathrm{COOC}_{2} \mathrm{H}_{5}$ and $\mathrm{CH}_{3} \mathrm{COOC}_{2} \mathrm{H}_{5}: \mathrm{CH}_{3} \mathrm{OH}$ to yield 20 fractions. Six fractions showed antibacterial activity against Candida albicans ATCC 10231 by Oxford Cup method, especiallyc the $10^{\text {th }}$ fraction showed stronger antibacterial activity, the diameters of inhibition zones of which was $36.0 \pm 2.0 \mathrm{~mm}$, while the others did not show activity (Fig.2, Table 1). These fractions with anti-Candida albicans activity were repeatly purifed by silica gel column, ODS column, Sephadex LH-20 column, and HPLC to offer compound 1 (7.7 mg), compound 2 (24.2mg), compound 3 (34.1 mg) and compound 4 ( $35.9 \mathrm{mg}$ ).

\section{Identification of Compounds}

Compound 1, orange powder; HR-ESI-MS m/z $1255.46[\mathrm{M}+\mathrm{H}]+, \mathrm{m} / \mathrm{z} 1277.39[\mathrm{M}+\mathrm{Na}]+$. Compound 2, orange powder; HR-ESI-MS m/z 1269.42[M+H] +, m/z 1291.44 [M+Na] +. Compound 3, white solid; HR-ESI-MS m/z 1086.51[2M+H] +, m/z 1107.43 [M+Na] +. Compound 4, colorless needle-like solid; HR-ESI-MS m/z 227.15 [M+H] +. The chemical structure of compounds 1-4 was identified based on the spectral information relating to ${ }^{1} \mathrm{H}$ NMR and ${ }^{13} \mathrm{C}$ NMR spectral data (See Supplementary), which were respectively confirmed to be Actinomycin D (1), Actinomycin $\mathrm{X}_{2}(2)$, Mojavensin A (3) and cyclic (leucine-leucine) dipeptide (4) by comparing the microspectrum, SciFinder and related references( Fig. 3).

\section{Antibacterial activity of Compounds}

The MIC experiment found that compounds 1-4 have broad spectrum antibacterial activity (Table

2), especially compound 3 Mojavensin A had the best effect on the four kinds of the tested fungi: Candida albicans, Trichophyton rubrum, Aspergillus fumigatus and Aspergillus niger. Compound 4 (leucine) -Leucine) dipeptide has the strongest inhibitory effect on E. coli, at $32 \mu \mathrm{g} / \mathrm{mL}$. In addition, 
compounds 1 Actinomycin D and compounds 2 Actinomycin X2 have the best effects against MRSA (ATCC 43300), with an inhibitory effect of $0.25 \mu \mathrm{g} / \mathrm{mL}$.

Interestingly, Mojavensin A and cyclic (leucine-leucine) dipeptide, which were separated from the tenth fraction with the strong activity against Candida albicans (Fig.4), mixed with different proportions had stronger activity against Candida albicans than every single compound. When the ratio was $1: 1$, the activity against Candida albicans was the strongest, but it still did not reach the strength of the tenth fraction(Table 3).

\section{Cytotoxicity of Compounds}

Cytotoxicity of Compounds 1-3 Actinomycin D, Actinomycin $\mathrm{X}_{2}$ and Mojavensin A for HepG-2 and CNE-2 cells was performed by MTT at different time. Results show that compounds 1-3 could inhibited cell proliferation in a time-dependent manner(Fig.5). Meanwhile the inhibitory effect of them for HepG-2 had the concentration correlation. The antiproliferative effect of Actinomycin D and Actinomycin $\mathrm{X}_{2}$ was more effectively than Mojavensin A at the Concentration of less than $50 \mu \mathrm{g} / \mathrm{ml}$. According to the inhibition rate of different concentrations, the half-maximal inhibitory concentration (IC50) of the compounds on HepG-2 and CNE-2 cells were calculated using the probability distribution of SPSS13.0 (Table 4).

\section{Discussion}

The growing resistance of microorganisms towards antibiotics has become a serious problem around the world. Terapeutics with novel chemical scaffolds and/or mechanisms of action are urgently needed to combat infections caused by multidrug resistant pathogens, including bacteria, fungi and viruses. Development of novel antimicrobial agents still highly depends on the new natural products. At present, most antimicrobial drugs used in medicine are of natural origin. Among the natural 
producers of bioactive substances, Actinobacteria continue to be an important source of novel secondary metabolites for drug application[22]. It was estimated that from the first report of streptothricin in 1942 and streptomycin a year later, the order Actinomycetales had yielded about 3000 known antibiotics[23]. However, with the known antibiotics are discovered repeatedly, there are fewer new antibiotics found from Streptomyces. Rare actinomycetes have been paid more attention as the hope of discovering new antibiotics. 167 new bioactive compounds produced by 58 different rare actinomycete species representing 24 genera. A total of 97 new species, representing 9 novel genera and belonging to 27 families of marine rare actinomycetes had been reported from mid-2013 to 2017[24]. About 20 years ago, rare actinomycete Gordonia was described as a genus, and there are 39 different species have been identified so far[25]. Some Gordonia species cause a broad spectrum of diseases in healthy and immunocompromised individuals. Besides, these bacteria can produce useful secondary metabolites that may be used in various industries[26].

In this study, we validated the endogenous Gordonia isolated from the intestinal tract of Periplaneta americana by sequence and phylogenetic tree construction and we named this Gordonia strain WA 4-31. Phylogenetic data showed that the strain WA 4-31 was $100 \%$ homologous to Gordonia from the Indian desert. Colony conformed to the biomarker of Gordonia by colony phenotype. Previous studies have shown that the endogenous environment of insects is unique and the natural products form the endogenous environment of insects may be different from the common environment in the land. Therefore, it is speculated that insect endophytes may produce precious and interesting natural compounds[27-29]. Insects are a highly diverse group, exploit a wide range of habitats, and harbor bacterial symbionts of largely unknown diversity. Insect-associated bacterial symbionts are underexplored but promising sources of bioactive compounds[30]. Lee SR et al. reported the discovery 
of three new cyclic tripeptides: natalenamides A-C[31]. These compounds were identified from the culture broth of the fungus-growing termite-associated Actinomadura sp. RB99. Li TX et al. reported two new compounds, versicolones A and B and three known pyrone derivatives were isolated from the insect-associated fungus Aspergillus versicolor[32]. At the present study, four antimicrobial compounds were isolated from the secondary metabolite of the strain WA4-31. Although these compounds, Actinomycin D, Actinomycin X2 and Mojavensin A were reported, which found in Gordonia is the first time. There was no report that they were found in secondary metabolites at the same time so far.

In our study, Actinomycin D and Actinomycin $\mathrm{X}_{2}$ showed extremely strong activity on MRSA, reached $0.25 \mu \mathrm{g} / \mathrm{mL}$ respectively, which was consistent with the existing reports[33-34]. These two Actinomycins showed general resistance to the remaining tested pathogens, which was different, compared with some reports. Xiong et al. found that Actinomycin $\mathrm{X}_{2}$ had strong antibacterial activity against several Gram-positive and Gram-negative bacteria examined (Staphylococcus aureus, Pseudomonas solanacearum, Escherichia coli, etc.) and was especially effective against $S$. aureus, with MIC50, $0.002 \mu \mathrm{g} / \mathrm{ml} ;$ MIC90, $0.017 \mu \mathrm{g} / \mathrm{mL}[35]$. Actinomycin D from the study by Zhang et al. were evaluated for their activity against the growth of methicillin-resistant S. aureus, E. coli, and C. albicans using the micro broth dilution method and the results showed that Actinomycin D significantly inhibited the growth of both bacteria and fungi with MIC values of 0.08 to $9.96 \mu \mathrm{M}[36]$. Among compounds, Mojavensin A had the best inhibitory activity against Aspergillus niger, Trichophyton rubrum and Aspergillus fumigatus, reaching $32 \mu \mathrm{g} / \mathrm{mL}, 16 \mu \mathrm{g} / \mathrm{mL}$ and $64 \mu \mathrm{g} / \mathrm{mL}$. The inhibitory effect of compound 3 Mojavensin A on Escherichia coli was $32 \mu \mathrm{g} / \mathrm{mL}$. Mojavensin A was found in 2012 for the first time[37]. In another report said mojavensins displayed moderate antagonism and dose-dependent activity against several formae speciales of Fusarium oxysporum and presented surface 
tension activities. These properties demonstrated that these lipopeptides may be useful as biological control agent to fungal plant pathogens[38]. These reports provided good evidence for our study on antibacterial activity in this article. The antibacterial activity of compound 1-3 against Candida albicans ranged from $32-128 \mu \mathrm{g} / \mathrm{mL}$.

In addition, we found a more interesting phenomenon. In the process of separating and purifying the secondary metabolites of strain WA 4-31, it was found that one of the fractions showed strong activity against Candida albicans ( Fig. 2; Table 1). Compound 3 Mojavensin A and compound 4 cyclic (leucine-leucine) dipeptide were obtained by further separation and purification from this fraction. The anti-Candida albicans activity of these two compounds was determined, and the activity of single compound was not outstanding. Then we mixed these two compounds according to different proportions, and it was found that the activity was obviously improved, but it still did not reach the strength of the fraction (Fig.4; Table 3). Antimicrobial resistance threatens a resurgence of life-threatening bacterial infections and the potential demise of many aspects of modern medicine. In order to delay the problem of antimicrobial resistance, people have extensively studied the synergistic effect of drugs in recent years. Combinations of antibiotics and of antibiotics with non-antibiotic activity-enhancing compounds offer a productive strategy to address the widespread emergence of antibiotic-resistant strains[39-40]. As there are still other complex bioactive components in the fractions that have not been separated, the synergistic effect and its mechanism among the specific compounds with strong anti-Candida albicans activity have not yet been determined, which needs further study. The inhibitory activities of all compounds on different bacteria and fungi were not consistent, so it was speculated that their coexistence was complementary for the host. Perhaps the host used them to fight against different pathogenic microorganisms to adapt to various living environments. 
At the same time, it also showed that the diversity and richness of secondary metabolites were conducive to the adaptation of microorganisms to their living environment for microorganisms themselves, which is of great significance[41].

In the cytotoxicity test, the cytotoxic effects of compounds 1-3 on different various of cells were different, and most of them were time-dependent or concentration-dependent. In the previous studies, Atinomycin D had a good anti-cancer effect on specific cancer cells, but its toxic and side effects limit its wide use[42, 43]. In this study, Actinomycin D could inhibit CNE-2 cells proliferation within $24 \mathrm{~h}$, reaching its peak at $72 \mathrm{~h}$. The inhibition of Actinomycin $\mathrm{X}_{2}$ on CNE-2 cells growth was not concentration-dependent, but time-dependent. Two kinds of Actinomycins inhibited the growth of HepG-2 cells in a time-dependent manner. At 48-72 h, Actinomycin $\mathrm{X}_{2}$ with higher concentration had obvious inhibitory effect on the growth of HepG-2 cells. We know that the structures of Actinomycin D and Actinomycin $\mathrm{X}_{2}$ are similar, but they showed inconsistent anticancer effects in this study. Actinomycin D has worked well in the treatment of Wilms tumors and neuroblastoma, and low-dose agents have been clinically applied[44]. About Actinomycin $\mathrm{X}_{2}$, it was reported that apoptosis of human prostate cancer cells could be induced by marine Actinomycin $\mathrm{X}_{2}$ but was not widely used in clinic[45]. At present, there is no research report about the anticancer effects of Actinomycin D and Actinomycin X2 on these two cancer cells. Mojavensin A can promoted the growth of HepG-2 cells within $24 \mathrm{~h}$, with a certain concentration correlation. However, after $48 \mathrm{~h}$, Mojavensin A began to inhibit the growth of HepG-2 cells. The inhibitory effect of Mojavensin A on the growth of CNE-2 cells had obvious time dependence. There were very few reports about anti-cancer research of Mojavensin A, only one report revealed cytotoxic activities of Mojavensin A against the human leukemia (HL-60) cells line, with $\mathrm{IC}_{50}$ of $100 \mu \mathrm{M}[37]$. Through this work, we hope to provide some research basis for the 
anti-cancer activities of these compounds. The mechanism of inhibiting proliferation of cancer cells are still unclear and need further study.

Through our work, we identified a rare actinomycete strain WA 4-31 from the intestinal tract of Periplaneta americana as Gordonia. Four compounds with antibacterial activity, Actinomycin D, Actinomycin $\mathrm{X}_{2}$ and Mojavensin A, were isolated and purified from the secondary metabolites of the strain WA 4-31. We determined their antibacterial activity and inhibitory effect on CNE-2 cells and HepG-2 cells. In the experiment of determining the anti-Candida albicans activity, we found that Mojavensin A and cyclic (leucine-leucine) dipeptide had a synergistic effect after being mixed in different proportions, which could enhance the anti-Candida albicans activity. This phenomenon was a good enlightenment for us, maybe we can continue our in-depth study in the follow-up study on antibacterial activity.

\section{Material and Methods}

\section{Microorganisms, Cell lines}

The Gordonia Strain WA 4-31(MH613773) was isolated from the intestinal tract of Periplaneta americana and saved by Guangdong Key Laboratory of Pharmaceutical Bioactive Substances. The tested strain including four kinds of pathogenic fungi: Candida albicans ATCC 10231, Trichophyton rubrum ATCC 60836, Aspergillus niger ATCC 16404, Aspergillus fumigatus ATCC 96918, and four kinds of pathogenic bacteria: methicillin-resistant Staphylococcus aureus (MRSA) ATCC 43300, Staphylococcus aureus ATCC 25923, Escherichia coli ATCC 25922 and Pneumobacillus ATCC 13883, were obtained from Guangdong Institute of Microbiology. CNE-2 Human nasopharyngeal carcinoma cell line, HepG2 human hepatocellular carcinoma cells were purchased from Experimental Animal Center of Sun Yat-sen University and Shanghai Cell Biology Institutes respectively. 


\section{Media and Chemicals}

Microbiological media were purchased from Guangdong Huankai Microbial Co. The genomic DNA isolation kit was purchased from TIANGEN Biotech. High-performance liquid chromatography (HPLC) grade methanol was purchased from ThermoFisher. Silica gel used for extraction and column chromatography were obtained from Qingdao Ocean Chemical Co. Sephadex LH-20 dextran gel, CHP20P MCI and DIASOGEL ODS were purchased from Mitsubishi Chemical Co. of Japan. Solvents used for extraction and column were of analytical grade which were obtained from Guangdong Guanghua Sci-Tech Co.

\section{Identification of Gordonia Strain WA 4-31}

The Gordonia strain WA 4-3 was inoculated on Gauze's No. 1 medium and incubate at $28^{\circ} \mathrm{C}$ for 3 days. Three days later, the single colony was selected and cultivated in the ISP-1 seed medium at $28^{\circ} \mathrm{C}$ for 2 days. The morphology and surface characteristics of the bacterial colonies were examined using a scanning electron microscope (Hitachi S-3400N, Japan). Whole genomic DNA of the strain was extracted according to the manufacturer's instructions of the genomic DNA isolation kit. The 16S rDNA gene was then amplifified by PCR, using universal bacterial primer (27F: 5'-AGA GTT TGA TCC TGG CTC AG-3' and 1492R: 5'-TAC GGC TAC CTT GTT ACGACT T-3'). PCR products were visualized by electrophoresis and was sequenced in BGI. The resulting sequence was compared to all sequences available in GenBank using the BLAST software from the National Center for Biotechnology Information (NCBI) website (http://www.ncbi.nlm.nih.gov/). The phylogenetic tree was constructed by MEGA.

\section{Production and Isolation of Secondary Metabolites from Strain WA 4-31}

The ISP 2 medium was used as the production culture. A $9 \mathrm{~mL}$ portion of the seed culture was 
transferred into a $500-\mathrm{mL}$ Erlenmeyer flask containing $300 \mathrm{~mL}$ of the ISP 2 medium and incubated on rotary shakers $(160 \mathrm{rpm})$ at $28^{\circ} \mathrm{C}$ for 21 days. The total $63 \mathrm{~L}$ of culture broth was extracted 3 times with an equivalent volume of ethyl acetate. After extraction and evaporation, $13.4 \mathrm{~g}$ crude ethyl acetate extract was obtained. The crude ethyl acetate of the strain WA 4-31 was separated to given 20 major fractions (1-20) using silica gel. The crude extract and every fraction were tested for antimicrobial activity against Candida albicans ATCC 10231 by Oxford Cup method[46]. Finally, the active fractions were further purifified by ODS column chromatography, Sephadex LH-20 column, and high-performance liquid chromatography (HPLC) to offer compounds.

\section{Spectroscopic Analysis}

The molecular weight of the purified compounds was determined using mass spectrometry and their structure was characterized by $1 \mathrm{H}$ NMR and 13C NMR. The compounds were fully dissolved in methanol with a concentration of about $1 \mathrm{mg} / \mathrm{L}$, filtered with a $0.22 \mu \mathrm{m}$ filter membrane, and then mass spectra was obtained within the range of $\mathrm{m} / \mathrm{z} 100-1500$ by TSQ Endura ${ }^{\mathrm{TM}}$ Triple-quadrupole mass spectrometer (Thermo Scientific, USA ). Selecting appropriate $600 \mu \mathrm{L}$ of deuterated reagent to dissolve $10.0 \mathrm{mg}$ of the compounds, the proton and carbon nuclear magnetic resonance (NMR) spectra were recorded at $600 \mathrm{MHz}$ using a Brucker AVANCE III 600M spectrometer (Brucker, Germany).

\section{Determination of minimum inhibitory concentration (MIC)}

Minimum inhibitory concentration (MIC) measurements of compounds against the tested strain were performed by a microdilution method. The compounds were dissolved in DMSO and then diluted by the twofold dilution method. One hundred microliters of bacterial suspension or fungi suspension $\left(10^{6} \mathrm{CFU} / \mathrm{mL}\right)$ were added to the 96 -well plates. Then one hundred microliters of compounds were added to the 96-well plates respectively. The fifinal concentrations of each sample in the wells were 
512, 256, 128, 64, 32, 16, 8, 4, 2, 1, 0.5 and $0.25 \mu \mathrm{g} / \mathrm{mL}$. Amphotericin B, Vancomycin, Ampicillin and Ciprofloxacin were used as positive drugs for fungi, MRSA, Pneumococcus and Escherichia coli respectively. The MIC value of the compounds was determined as the lowest concentration that completely inhibited bacterial growth after $48 \mathrm{~h}$ of incubation at $37^{\circ} \mathrm{C}$, while the fungi was incubated at $28^{\circ} \mathrm{C}$. All experiments were performed in triplicate.

\section{Filter paper diffusion method}

Antibacterial activity against Candida albicans was tested using the filter paper diffusion method. Sterile fifilter paper discs $(6 \mathrm{~mm})$ were taken, soaked sufficiently in different samples for 5 min and set aside. Bacterial suspensions were dipped with sterile cotton, and uniformly applied in the culture media. Fully soaked filter paper was placed in the bacteria containing plates and cultured for $24 \mathrm{~h}$ in the $28^{\circ} \mathrm{C}$ constant temperature incubator. Amphotericin B $(32 \mu \mathrm{g} / \mathrm{mL})$ was used as positive control. The experiment was performed in triplicate and the mean of the diameter of the inhibition zones was calculated.

\section{Cells viability assay}

Cellular viability was evaluated with the MTT (Amresco, USA) assay. $5 \times 10^{3}$ cells suspended in $100 \mu \mathrm{l}$ DMEM medium were added into a 96-well plate and treated with different concentrations of compounds for $24 \mathrm{~h} / 48 \mathrm{~h} / 72 \mathrm{~h}$. After then, $10 \mu \mathrm{L}$ of $0.5 \mathrm{mg} / \mathrm{mL}$ MTT reagent was added to each well for an additional $4 \mathrm{~h}$. The purple formazan crystals were dissolved with $100 \mu \mathrm{L}$ DMSO per well for further quantitative measurement at an absorbance of $570 \mathrm{~nm}$ using a microplate spectrophotometer. Experiments were independently repeated three times.

\section{Abbreviations}


MRSA: Methicillin-resistant Staphylococcus aureus; HPLC: High Performance Liquid

Chromatography; NMR: Nuclear Magnetic Resonance; HR-ESI-MS: High-resolution electrospray ionization mass spectroscopy; EtOAc: Ethyl acetate; MEGA: Molecular Evolutionary Genetics

Analysis; DMSO: Dimethyl Sulfoxide; CFU: Colony-forming Unit

\section{Acknowledgment}

The authors gratefully acknowledges Ph.D Xiongming Luo for analyzing the results of compounds.

\section{Authors' contributions}

XJ devised and supervised the experiments. MX, HL, TY and PG participated in the experiments. WL analyzed data. YM, MX wrote the manuscript. All authors read and approved the manuscript.

\section{Funding}

This work was funded by the Public Welfare Research and Capacity Building Project of Guangdong Province (No. 2016A030303059 and No. 2017A020211008), and the Key Projects of Basic Research and Applied Basic Research of Guangdong Province Normal University（No. 2018KZDXM041）

\section{Availability of data and materials}

All data generated or analyzed during this study are included in this published article and its supplementary information files.

\section{Ethics approval and consent to participate}

This article does not contain any studies with human participants or vertebrates performed by any of the authors.

\section{Consent for publication}

Not applicable.

\section{Competing interests}


The authors declare that they have no competing interests.

\section{Author details}

1 School of Life Sciences and Biopharmaceutics, Guangdong Pharmaceutical University, Guangzhou,

510006, China; 2 Guangdong Provincial Key Laboratory of Pharmaceutical Bioactive Substances,

Guangdong Pharmaceutical University, Guangzhou, 510006, China

\section{References}

1. Sayed AM, Hassan MHA, Alhadrami HA, Hassan HM, Goodfellow M, Rateb ME. Extreme environments: microbiology leading to specialized metabolites. J Appl Microbiol. 2020; 128(3):630-657.

27. Beemelmanns C, Guo H, Rischer M, Poulsen M. Natural products from microbes associated with insects. Beilstein J Org Chem. 2016; 12:314-327.

2. Sivalingam P, Hong K, Pote J, Prabakar K. Extreme Environment Streptomyces: Potential Sources for New Antibacterial and Anticancer Drug Leads? Int J Microbiol. 2019; 5283948.

3. Zain Ul Arifeen M, Ma YN, Xue YR, Liu CH. Deep-Sea Fungi Could Be the New Arsenal for Bioactive Molecules. Mar Drugs. 2019; 18(1):9.

4. Durán P, Barra PJ, Jorquera MA, Viscardi S, Fernandez C, Paz C, Mora ML, Bol R. Occurrence of Soil Fungi in Antarctic Pristine Environments. Front Bioeng Biotechnol. 2019; 7:28.

5. Velez P, Espinosa-Asuar L, Figueroa M, Gasca-Pineda J, Aguirre-von-Wobeser E, Eguiarte LE, Hernandez-Monroy A, Souza V. Nutrient Dependent Cross-Kingdom Interactions: Fungi and Bacteria From an Oligotrophic Desert Oasis. Front Microbiol. 2018; 9:1755.

6. Riahi K, Hosni K, Raies A, Oliveira R. Unique secondary metabolites of a Streptomyces strain isolated from extreme salty wetland show antioxidant and antibacterial activities. J Appl 
Microbiol. 2019; 127(6):1727-1740.

7. Peng F, Zhang MY, Hou SY, Chen J, Wu YY, Zhang YX. Insights into Streptomyces spp. Isolated from the rhizospheric soil of Panax notoginseng: isolation, antimicrobial activity and biosynthetic potential for polyketides and non-ribosomal peptides. BMC Microbiol. 2020; 20(1 ): 143.

8. Torres-Mendoza D, Ortega HE, Cubilla-Rios L. Patents on Endophytic Fungi Related to Secondary Metabolites and Biotransformation Applications. J Fungi (Basel). 2020; 6(2):58.

9. Tanvir R, Javeed A, Bajwa AG. Endophyte bioprospecting in South Asian medicinal plants: an attractive resource for biopharmaceuticals. Appl Microbiol Biotechnol. 2017; 10(5) :1831-1844.

10. Kamel NM, Abdel-Motaal FF, El-Zayat SA. Endophytic fungi from the medicinal herb Euphorbia geniculata as a potential source for bioactive metabolites. Arch Microbiol. 2020; 202(2):247-255.

11. Mastan A, Vivek Babu CS, Hiremath C, Srinivas KVNS, Kumar AN, Kumar JK. Treatments with native Coleus forskohlii endophytes improve fitness and secondary metabolite production of some medicinal and aromatic plants. Int Microbiol. 2020; 23(2):345-354.

12. Martinez-Klimova E, Rodríguez-Peña K, Sánchez S. Endophytes as sources of antibiotics. Biochem Pharmacol. 2017; 134:1-17.

13. Silva FA, Liotti RG, Boleti APA, Reis ÉM, Passos MBS, Dos Santos EL, Sampaio OM, Januário AH, Branco CLB, Silva GFD, Mendonça EAF, Soares MA. Diversity of cultivable fungal endophytes in Paullinia cupana (Mart.) Ducke and bioactivity of their secondary metabolites. PLoS One. 2018; 13(4):e0195874.

14. Zheng Y, Xiao G, Zhou W, Gao Y, Li Z, Du G, Chen B. Midgut microbiota diversity of potato tuber moth associated with potato tissue consumed. BMC Microbiol. 2020; 20(1):58.

15. Xu X, Shao M, Yin C, Mao Z, Shi J, Yu X, Wang Y, Sun F, Zhang Y. Diversity, Bacterial Symbionts, 
and Antimicrobial Potential of Termite-Associated Fungi. Front Microbiol. 2020; 11:300.

16. Tanvir R, Sajid I, Hasnain S, Kulik A, Grond S. Rare actinomycetes Nocardia caishijiensis and Pseudonocardia carboxydivorans as endophytes, their bioactivity and metabolites evaluation. Microbiol Res. 2016; 185:22-35.

17. Guo H, Benndorf R, Leichnitz D, Klassen JL, Vollmers J, Görls H, Steinacker M, Weigel C, Dahse HM, Kaster AK, de Beer ZW, Poulsen M, Beemelmanns C. Isolation, Biosynthesis and Chemical Modifications of Rubterolones A-F: Rare Tropolone Alkaloids from Actinomadura sp. 5-2. Chemistry. 2017; 23(39):9338-9345.

19. 8Fang X, Shen J, Wang J, Chen ZL, Lin PB, Chen ZY, Liu LY, Zeng HX, Jin XB. Antifungal activity of 3-acetylbenzamide produced by actinomycete WA23-4-4 from the intestinal tract of Periplaneta americana. J Microbiol. 2018; 56(7):516-523.

19. Chen Z, Ou P, Liu L, Jin X. Anti-MRSA Activity of Actinomycin X2 and Collismycin A Produced by Streptomyces globisporus WA5-2-37 From the Intestinal Tract of American Cockroach (Periplaneta americana). Front Microbiol. 2020; 11:555.

20. Abidi S, Achar J, Assao Neino MM, Bang D, Benedetti A, Brode S, Campbell JR, Casas EC, Conradie F, Dravniece G, du Cros P, Falzon D, Jaramillo E, Kuaban C, Lan Z, Lange C, Li PZ, Makhmudova M, Maug AKJ, Menzies D, Migliori GB, Miller A, Myrzaliev B, Ndjeka N, Noeske J, Parpieva N, Piubello A, Schwoebel V, Sikhondze W, Singla R, Souleymane MB, Trébucq A, Van Deun A, Viney K, Weyer K, Zhang BJ, Ahmad Khan F. Standardised shorter regimens versus individualised longer regimens for rifampin- or multidrug-resistant tuberculosis. Eur Respir J. 2020; 55(3):1901467.

21. Shintani M, Sugiyama K, Sakurai T, Yamada K, Kimbara K. Biodegradation of A-fuel oil in soil 
samples with bacterial mixtures of Rhodococcus and Gordonia strains under low temperature conditions. J Biosci Bioeng. 2019; 127(2):197-200.

22. Jakubiec-Krzesniak K, Rajnisz-Mateusiak A, Guspiel A, Ziemska J, Solecka J. Secondary Metabolites of Actinomycetes and their Antibacterial, Antifungal and Antiviral Properties. Pol J Microbiol. 2018; 67(3):259-272.

23. Clardy J, Fischbach MA, Walsh CT. New antibiotics from bacterial natural products. Nat Biotechnol. 2006; 24(12):1541-1550.

24. Subramani R, Sipkema D. Marine Rare Actinomycetes: A Promising Source of Structurally Diverse and Unique Novel Natural Products. Mar Drugs. 2019; 17(5):249.

25. Sowani H, Kulkarni M, Zinjarde S. An insight into the ecology, diversity and adaptations of Gordonia species. Crit Rev Microbiol. 2018; 44(4):393-413.

26. Andalibi F, Fatahi-Bafghi M. Gordonia: isolation and identification in clinical samples and role in biotechnology. Folia Microbiol (Praha). 2017; 62(3):245-252.

28. Newman DJ, Cragg GM. Natural Products as Sources of New Drugs from 1981 to 2014. J Nat Prod. 2016; 79(3):629-661.

29. Chevrette MG, Carlson CM, Ortega HE, Thomas C, Ananiev GE, Barns KJ, Book AJ, Cagnazzo J, Carlos C, Flanigan W, Grubbs KJ, Horn HA, Hoffmann FM, Klassen JL, Knack JJ, Lewin GR, McDonald BR, Muller L, Melo WGP, Pinto-Tomás AA, Schmitz A, Wendt-Pienkowski E, Wildman S, Zhao M, Zhang F, Bugni TS, Andes DR, Pupo MT, Currie CR. The antimicrobial potential of Streptomyces from insect microbiomes. Nat Commun. 2019; 10(1):516.

30. Martinez AFC, de Almeida LG, Moraes LAB, Cônsoli FL. Microbial Diversity and Chemical Multiplicity of Culturable, Taxonomically Similar Bacterial Symbionts of the Leaf-Cutting Ant 
Acromyrmex coronatus. Microb Ecol. 2019; 77(4):1067-1081.

31. Lee SR, Lee D, Yu JS, Benndorf R, Lee S, Lee DS, Huh J, de Beer ZW, Kim YH, Beemelmanns C, Kang KS, Kim KH. Natalenamides $\mathrm{A}^{-} \mathrm{C}$, Cyclic Tripeptides from the Termite-Associated Actinomadura sp. RB99. Molecules. 2018; 23(11):3003.

32. Li TX, Meng DD, Wang Y, An JL, Bai JF, Jia XW, Xu CP. Antioxidant coumarin and pyrone derivatives from the insect-associated fungus Aspergillus Versicolor. Nat Prod Res. 2020; 34(10):1360-1365.

33. Rathod BB, Korasapati R, Sripadi P, Reddy Shetty P. Novel actinomycin group compound from newly isolated Streptomyces sp. RAB12: isolation, characterization, and evaluation of antimicrobial potential. Appl Microbiol Biotechnol. 2018; 102(3) :1241-1250.

34. Sharma M, Manhas RK. Purification and characterization of actinomycins from Streptomyces strain M7 active against methicillin resistant Staphylococcus aureus and vancomycin resistant Enterococcus. BMC Microbiol. 2019; 19(1):44.

35. Xiong ZQ, Zhang ZP, Li JH, Wei SJ, Tu GQ. Characterization of Streptomyces padanus JAU4234, a producer of actinomycin $\mathrm{X}_{2}$, fungichromin, and a new polyene macrolide antibiotic. Appl Environ Microbiol. 2012; 78(2):589-592.

36. Zhang XF, Ye XW, Chai WY, Lian XY, Zhang ZZ. New Metabolites and Bioactive Actinomycins from Marine-Derived Streptomyces sp. ZZ338. Mar Drugs. 2016; 14(10):181.

37. Ma Z, Wang N, Hu J, Wang S. Isolation and characterization of a new iturinic lipopeptide, mojavensin A produced by a marine-derived bacterium Bacillus mojavensis B0621A. J Antibiot (Tokyo). 2012; 65(6):317-322.

38. Ma Z, Hu J. Production and characterization of Iturinic lipopeptides as antifungal agents and 
biosurfactants produced by a marine pinctada martensii-derived Bacillus mojavensis B0621A. Appl Biochem Biotechnol. 2014; 173(3):705-715.

39. Tyers M, Wright GD. Drug combinations: a strategy to extend the life of antibiotics in the $21 \mathrm{st}$ century. Nat Rev Microbiol. 2019;17(3):141-155.

40. Zheng W, Sun W, Simeonov A. Drug repurposing screens and synergistic drug-combinations for infectious diseases. Br J Pharmacol. 2018;175(2):181-191.

41. Cheng MM, Tang XL, Sun YT, Song DY, Cheng YJ, Liu H, Li PL, Li GQ. Biological and Chemical Diversity of Marine Sponge-Derived Microorganisms over the Last Two Decades from 1998 to 2017. Molecules. 2020; 25(4):853.

42. Cortes CL, Veiga SR, Almacellas E, Hernández-Losa J, Ferreres JC, Kozma SC, Ambrosio S, Thomas G, Tauler A. Effect of low doses of actinomycin D on neuroblastoma cell lines. Mol Cancer. 2016; 15:1.

43. Lamture G, Crooks PA, Borrelli MJ. Actinomycin-D and dimethylamino-parthenolide synergism in treating human pancreatic cancer cells. Drug Dev Res. 2018; 79(6):287-294.

44. Ortiz MV, Fernandez-Ledon S, Ramaswamy K, Forlenza CJ, Shukla NN, Kobos R, Heaton TE, LaQuaglia MP, Steinherz PG. Maintenance chemotherapy to reduce the risk of a metachronous Wilms tumor in children with bilateral nephroblastomatosis. Pediatr Blood Cancer. 2019; 66(1): e27500.

45. Liu J, Xie S, Wu Y, Xu M, Ao C, Wang W, Zeng Q, Hu W, Li M. Apoptosis of human prostate cancer cells induced by marine actinomycin X2 through the mTOR pathway compounded by MiRNA144. Anticancer Drugs. 2016; 27(3):156-63.

46. Tao R, Wang CZ, Ye JZ, Zhou H, Chen HX, Zhang CW. Antibacterial, cytotoxic and genotoxic 
activity of nitrogenated and haloid derivatives of C50-C60 and C70-C120 polyprenol homologs. Lipids Health Dis. 2016; 15(1):175.

Fig. 1 Results of strain identification (a) Colonies of Strain WA4-31 on Gauze's medium. (b) Observation Results of Strain WA4-31 under Scanning Electron Microscope of 5000×. (c) Observation Results of Strain WA4-31 under Scanning Electron Microscope of 20000×. (d) Detection of PCR Products of 16S rDNA by Agarose Gel Electrophoresis. 1、2: Black control; 3、4:WA4-31 16S rDNA; 5:2000 DNA marker. (e) Phylogenetic Tree of Strain WA 4-31. Maximum-likelihood phylogenetic tree based on 16S rDNA gene sequences showing the positions of strain WA 4-31, the type strains of other Gordonia and representatives of some other related taxa. Only bootstrap values (expressed as percentages of 1,000 replications) greater than $50 \%$ are shown at branching points. Bar, 0.02 substitutions per nucleotide position.

Fig. 2 The antibacterial activity of different fractions against Candida albicans with Oxford Cup method (a) The $3^{\text {rd }}$ and the $4^{\text {th }}$ fractions had anti-Candida albicans activity, (b) while the $5^{\text {th }}$ and the $6^{\text {th }}$ did not, (c) The $10^{\text {th }}$ fraction had stronger antibacterial activity. 1: Positive drug: Amphotericin B, $32 \mu \mathrm{g} / \mathrm{mL}$; 2: Blank control: methanol solution; 3-7: Methanol solutions with different fractions, $5 \mathrm{mg} / \mathrm{mL}$.

Fig. 3 Molecular Structure of compound 1-4 (a) compound 1: Actinomycin D. (b) compound 2: Actinomycin $\mathrm{X}_{2}$. (c)compound 3: Mojavensin A. (d)compound 4: cyclic (leucine-leucine) dipeptide

Fig. 4 Activity of various samples against Candida albicans by Filter paper method 1: Positive drug: Amphotericin B, $32 \mu \mathrm{g} / \mathrm{mL} ; 2$ : Blank control: methanol solution; 3:the tenth fraction dissolved in methanol, $1 \mathrm{mg} / \mathrm{mL}$; 4: Mojavensin A dipeptide dissolved in methanol, $512 \mu \mathrm{g} / \mathrm{mL} ; 5$ : 
Cyclic (leucine-leucine) dipeptide dissolved in methanol, $512 \mu \mathrm{g} / \mathrm{mL}$; 6: Mojavensin A: cyclic (leucine-leucine) dipeptide $=2: 1 ; 7:$ Mojavensin A: cyclic (leucine-leucine) dipeptide =1: 1; 8:

Mojavensin A: cyclic (leucine-leucine) dipeptide =1: 2 .

Fig. 5 The cytotoxicity (MTT ASSAY) results of compounds on HepG-2cells (a) and CNE-2 cells(b) at the different concentrations for 24-72 $\mathrm{h}$ 


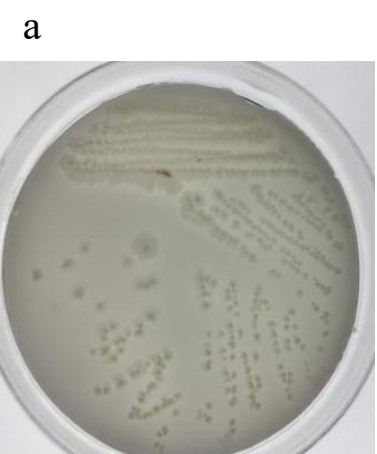

d

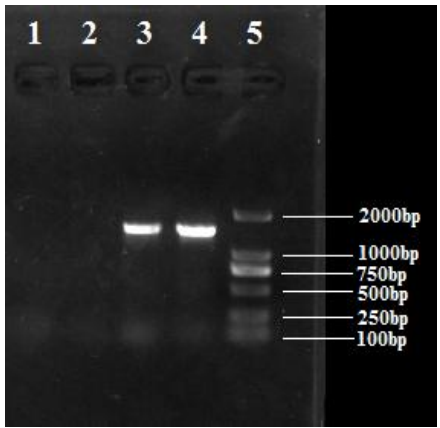

b

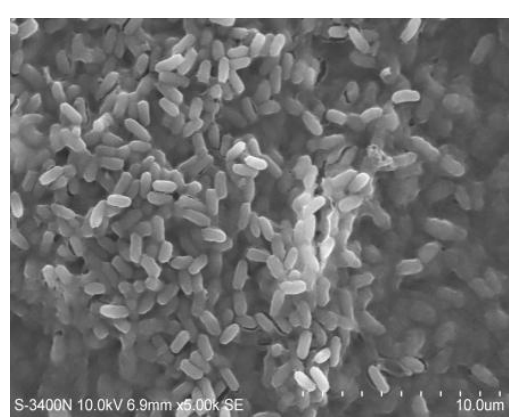

e

c
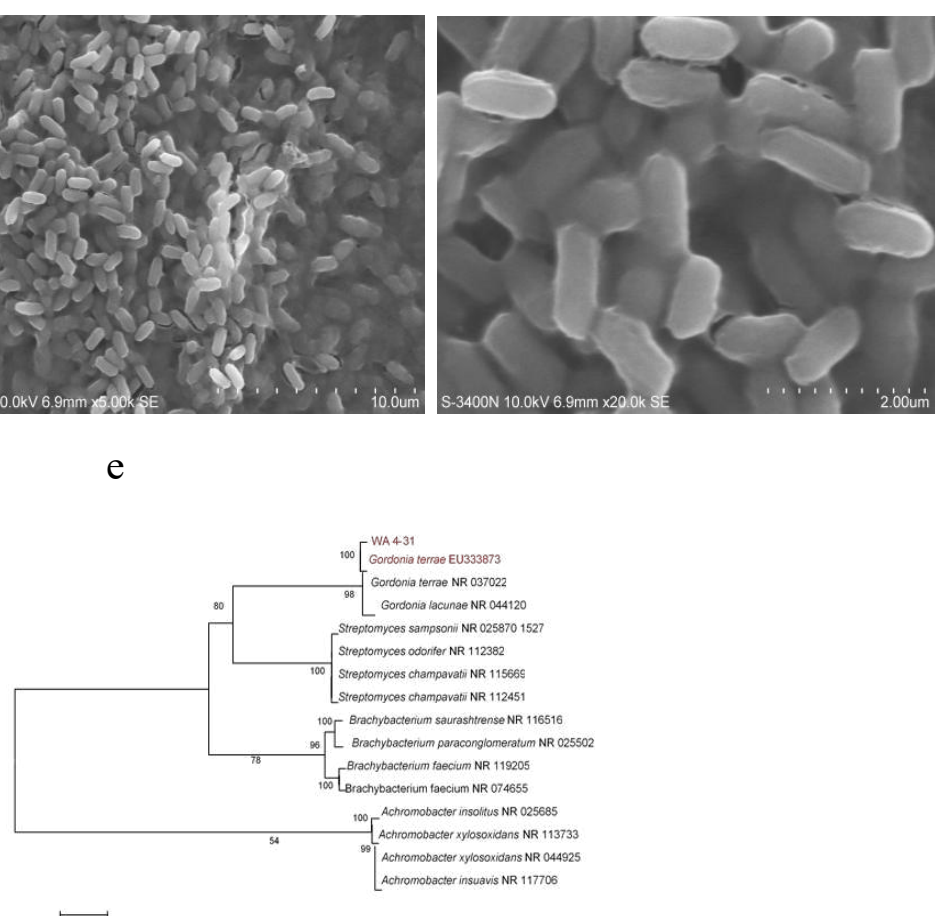

Fig. 1 


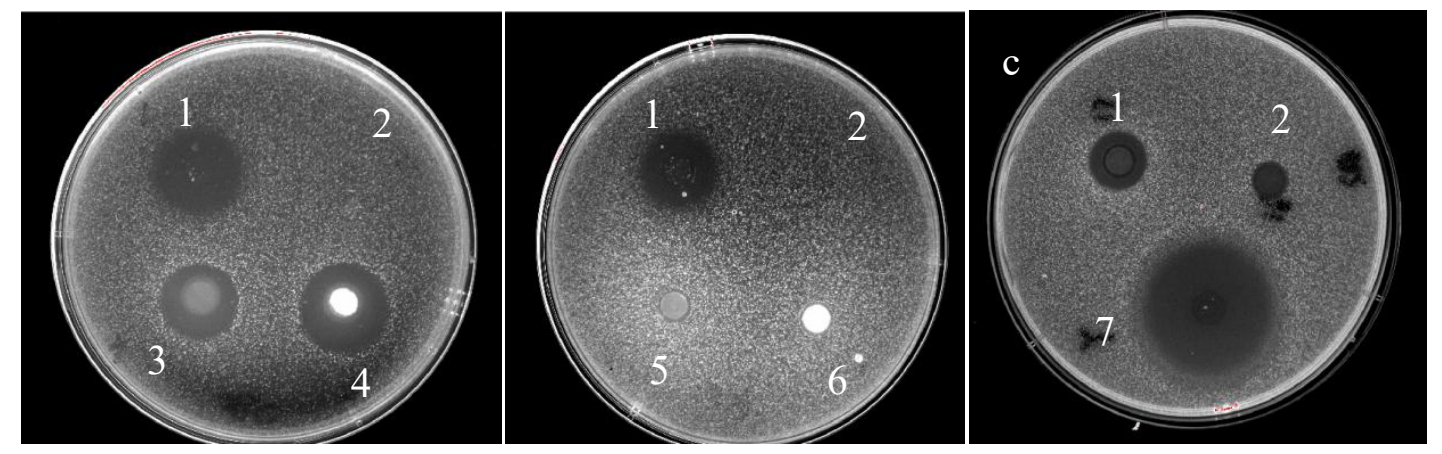

Fig. 2 

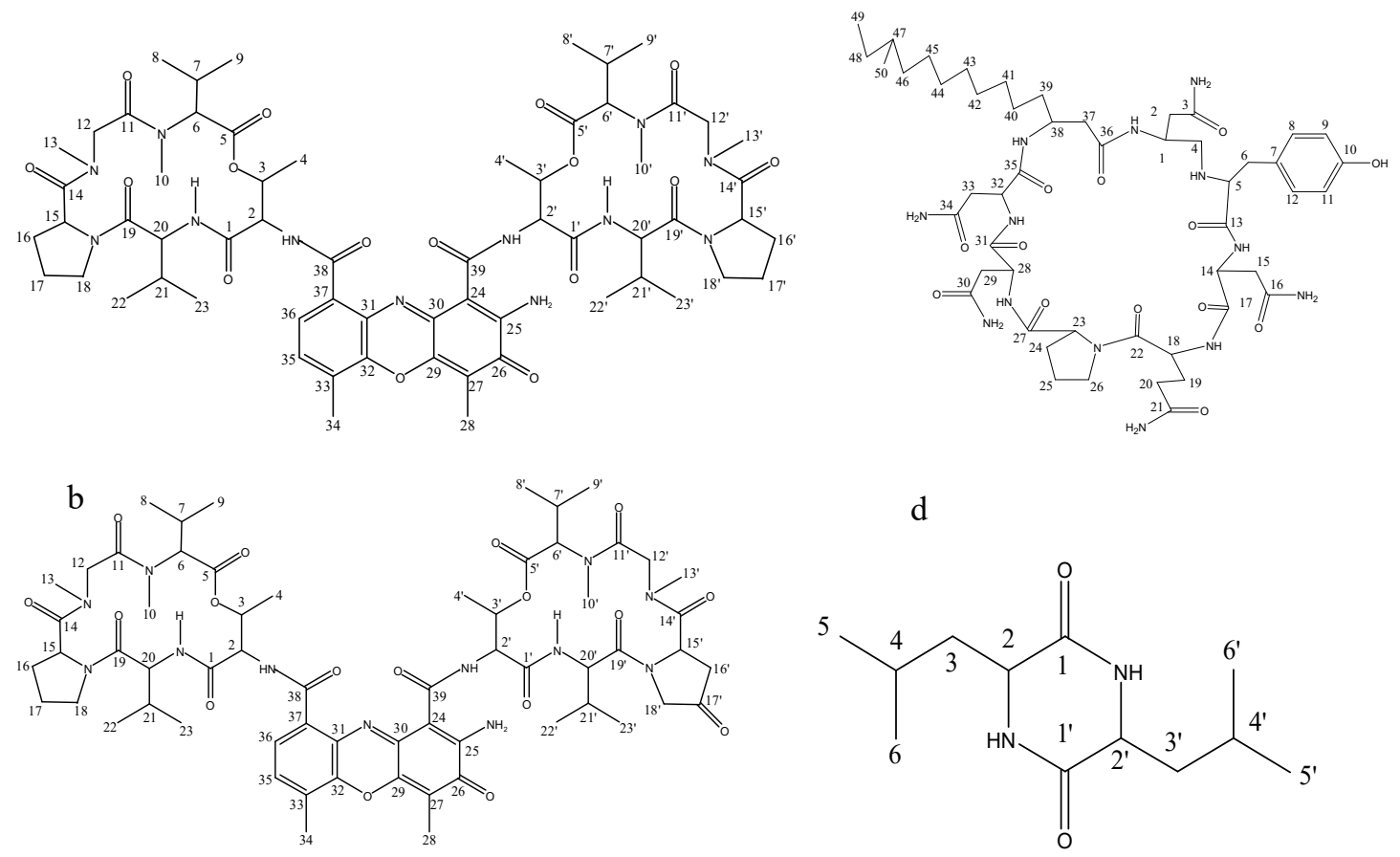

d

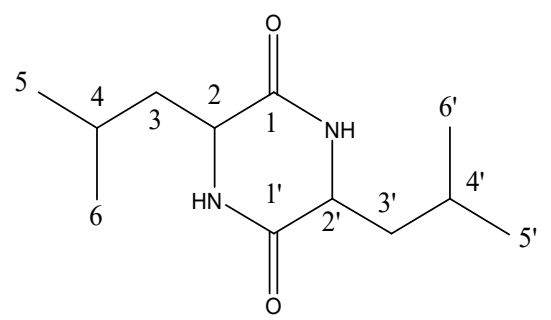

Fig. 3 


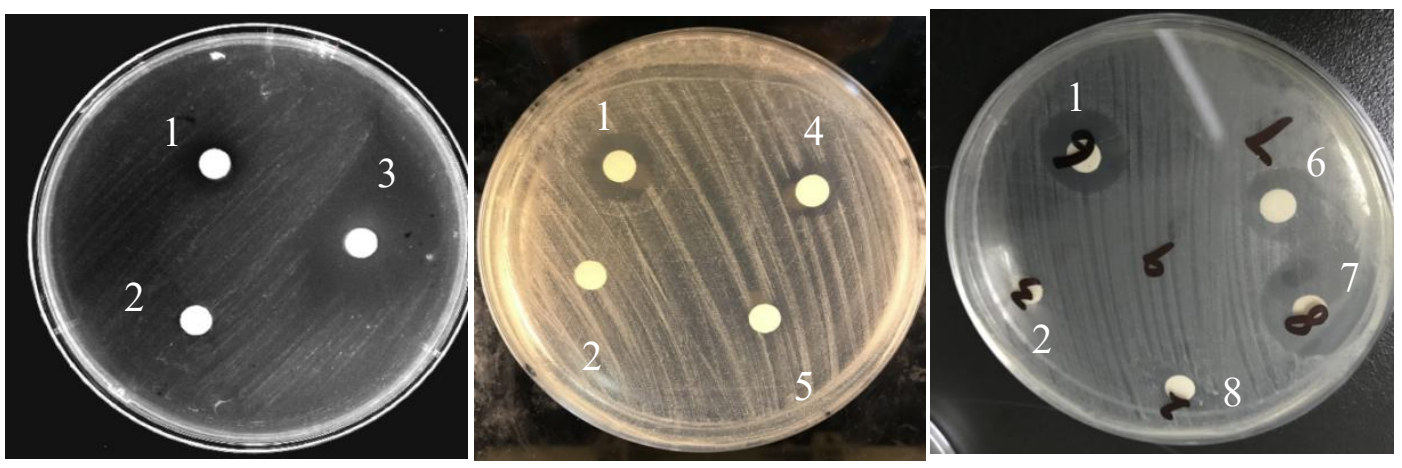

Fig. 4 

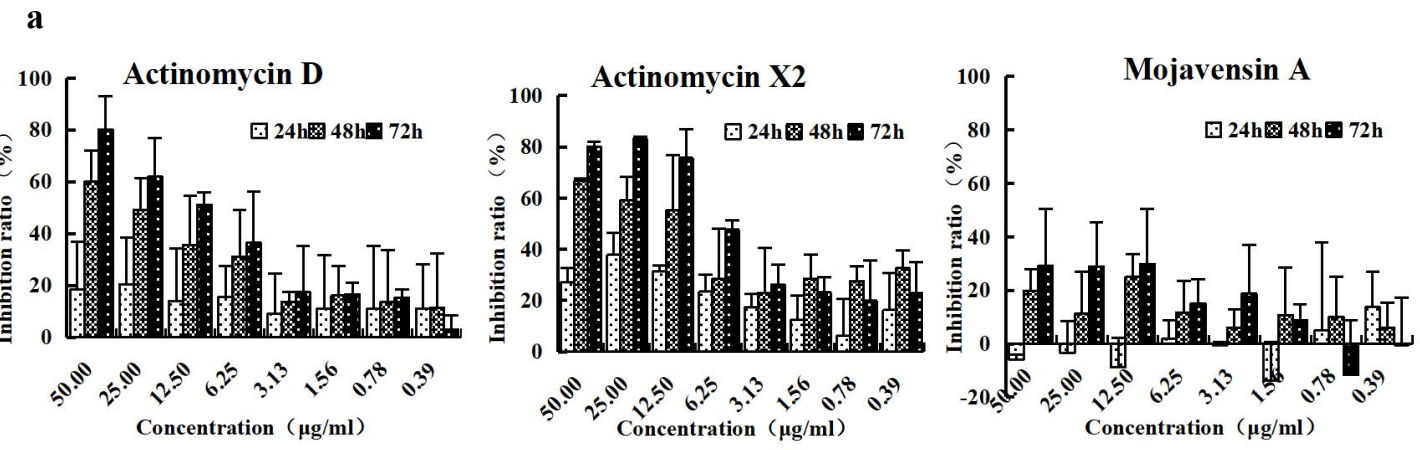

b
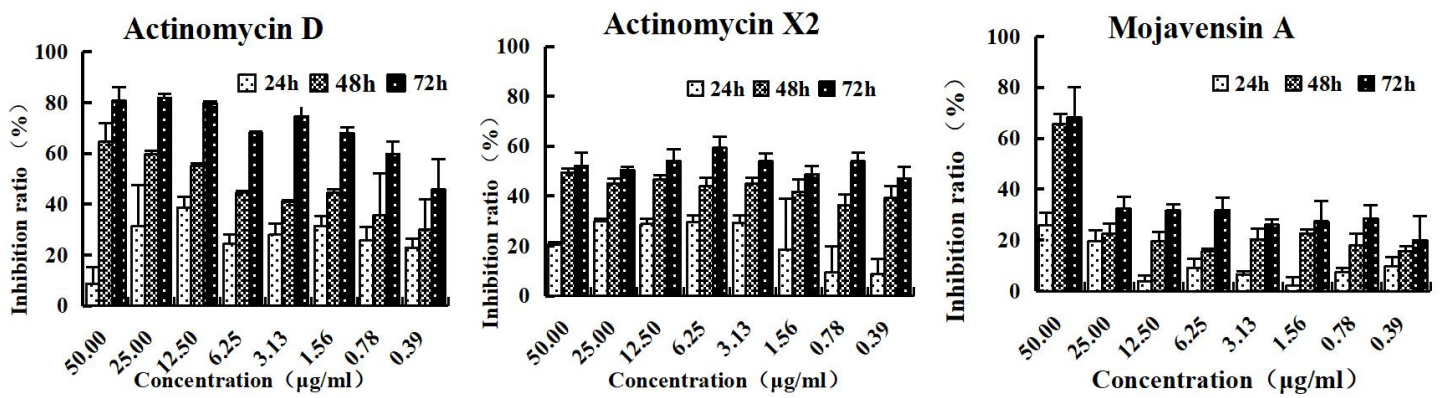

Fig. 5 
Table 1 The Inhibition Zone size of the fractions for Candida albicans with Oxford cups method

\begin{tabular}{|c|c|c|c|c|c|c|c|}
\hline & $\begin{array}{c}3^{\text {rd }} \\
\text { fraction }\end{array}$ & $\begin{array}{c}4^{\text {th }} \\
\text { fraction }\end{array}$ & $\begin{array}{c}10^{\text {th }} \\
\text { fraction }\end{array}$ & $\begin{array}{c}11^{\text {th }} \\
\text { fraction }\end{array}$ & $\begin{array}{c}15^{\text {th }} \\
\text { fraction }\end{array}$ & $\begin{array}{c}16^{\text {th }} \\
\text { fraction }\end{array}$ & $\begin{array}{c}\text { Positive } \\
\text { drug }\end{array}$ \\
\hline & \multicolumn{7}{|c|}{ Diameter of the inhibition zone $(\mathrm{mm})$} \\
\hline $\begin{array}{c}\text { Candida } \\
\text { albicans } \\
\text { ATCC } \\
10231\end{array}$ & $13.0 \pm 1.5$ & $10.5 \pm 1.0$ & $36.0 \pm 2.0$ & $16.0 \pm 1.0$ & $13.5 \pm 1.0$ & $12.0 \pm 1.5$ & $15.0 \pm 1.0$ \\
\hline
\end{tabular}

Table 2 The Minimal inhibitory concentration (MIC) of Compounds against the tested strains $(\mu \mathrm{g} / \mathrm{mL})$

\begin{tabular}{ccccc}
\hline & $\begin{array}{c}\text { Compound 1 } \\
\text { Actinomycin D }\end{array}$ & $\begin{array}{c}\text { Compound 2 } \\
\text { Actinomycin X2 }\end{array}$ & $\begin{array}{c}\text { Compound 3 } \\
\text { Mojavensin A }\end{array}$ & $\begin{array}{c}\text { Compound 4 } \\
\text { cyclic (leucine-leucine) } \\
\text { dipeptide }\end{array}$ \\
\hline $\begin{array}{c}\text { Candida albicans } \\
\text { ATCC 10231 }\end{array}$ & 32 & 128 & 64 & $>256$ \\
$\begin{array}{c}\text { Trichophyton rubrum } \\
\text { ATCC 60836 } \\
\text { Aspergillus niger } \\
\text { ATCC 16404 }\end{array}$ & 128 & 128 & 16 & $>256$ \\
$\begin{array}{c}\text { Aspergillus fumigatus } \\
\text { ATCC 96918 } \\
\text { MRSA }\end{array}$ & 128 & 128 & 32 & 128 \\
$\begin{array}{c}\text { ATCC43300 } \\
\text { S.aureus } \\
\text { ATCC25923 }\end{array}$ & 0.25 & 128 & 64 & $>256$ \\
$\quad \begin{array}{l}\text { E.coli } \\
\text { ATCC 25922 }\end{array}$ & 64 & 0.25 & $>256$ & $>256$ \\
$\begin{array}{c}\text { K.peneumoniae } \\
\text { ATCC 13883 }\end{array}$ & 64 & 128 & $>256$ & 32 \\
\hline
\end{tabular}


Table 3 The Inhibition Zone size of various samples against Candida albicans by Filter paper method

\begin{tabular}{cccccccc}
\hline & $\begin{array}{c}\text { compound 3 } \\
\text { Mojavensin } \\
\text { A }\end{array}$ & $\begin{array}{c}\text { compound } 4 \\
\text { cyclic } \\
\text { (leucine-leuci } \\
\text { ne) dipeptide }\end{array}$ & $\begin{array}{c}\text { Mojavensin A: } \\
\text { cyclic (leucine- } \\
\text { leucine) } \\
\text { dipeptide }=1: 1\end{array}$ & $\begin{array}{c}\text { Mojavensin A: } \\
\text { cyclic (leucine- } \\
\text { leucine) } \\
\text { dipeptide =2: } 1\end{array}$ & $\begin{array}{c}\text { Mojavensin A: } \\
\text { cyclic (leucine- } \\
\text { leucine) } \\
\text { dipeptide =1: } 2\end{array}$ & $\begin{array}{c}\text { The tenth } \\
\text { fraction }\end{array}$ & $\begin{array}{c}\text { Positive } \\
\text { drug }\end{array}$ \\
\cline { 2 - 7 } Diameter of the inhibition zone (mm) & $(\mathrm{n}=3$, means \pm SD) \\
$\begin{array}{c}\text { Candida } \\
\text { albicans } \\
\text { ATCC } \\
10231\end{array}$ & $8.5 \pm 0.5$ & - & $14.5 \pm 1.0$ & $11.5 \pm 1.5$ & $8.0 \pm 1.5$ & $19.0 \pm 1.0$ & $11.5 \pm 0.5$ \\
\hline
\end{tabular}

Table 4 The half-maximal inhibitory concentration $\left(\mathrm{IC}_{50}\right)$ of compounds on HepG-2 and CNE-2 cells for 24-72 h $(\mu \mathrm{g} / \mathrm{mL})$

\begin{tabular}{ccccccc}
\hline & \multicolumn{3}{c}{ HepG-2 } & \multicolumn{3}{c}{ CNE-2 } \\
\cline { 2 - 7 } & $24 \mathrm{~h}$ & $48 \mathrm{~h}$ & $72 \mathrm{~h}$ & $24 \mathrm{~h}$ & $48 \mathrm{~h}$ & $72 \mathrm{~h}$ \\
\hline Actinomycin D & $>200$ & 29.74 & 12.16 & $>200$ & 15.02 & 1.24 \\
Actinomycin $\mathbf{X}_{\mathbf{2}}$ & $>200$ & 14.68 & 5.37 & $>200$ & 84.38 & 0.93 \\
Mojavensin A & - & $>200$ & $>200$ & $>200$ & 130.72 & 51.03 \\
\hline
\end{tabular}




\section{Figures}

a

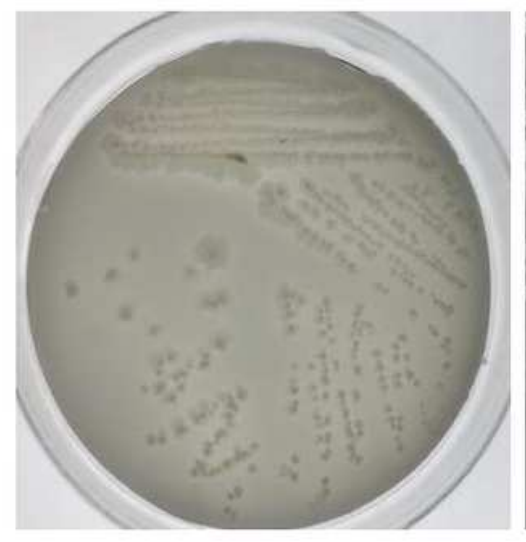

d

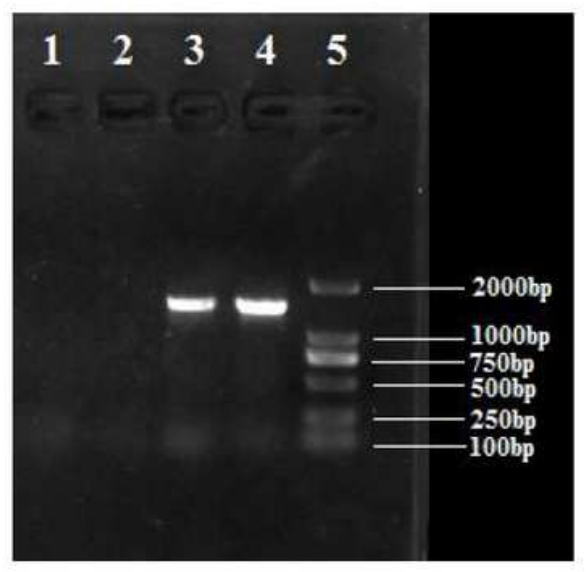

b

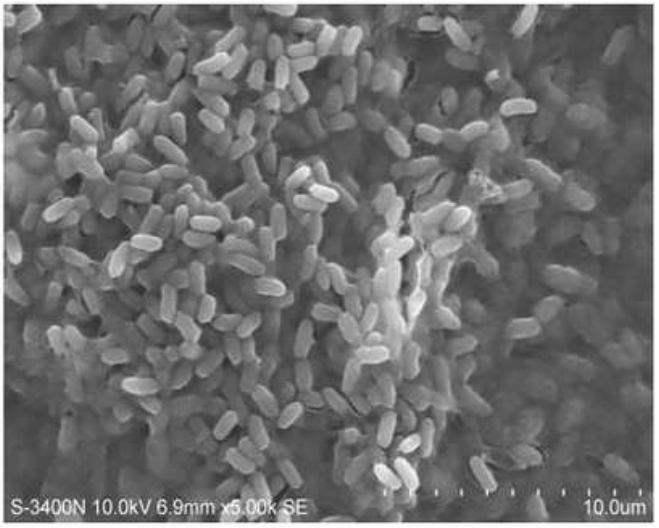

C

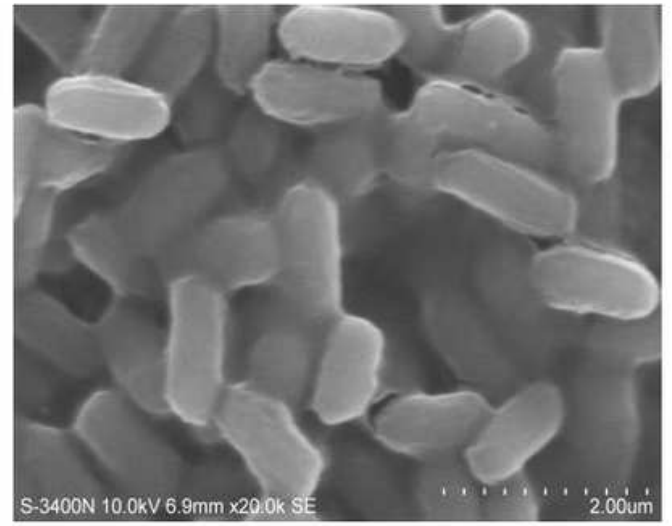

e

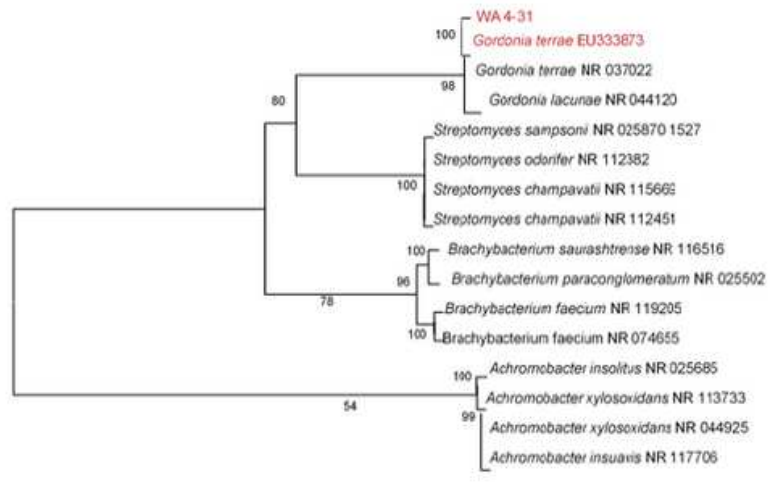

$\stackrel{\longmapsto}{~}$

\section{Figure 1}

Results of strain identification (a) Colonies of Strain WA4-31 on Gauze's medium. (b) Observation Results of Strain WA4-31 under Scanning Electron Microscope of 5000x. (c) Observation Results of Strain WA431 under Scanning Electron Microscope of 20000x. (d) Detection of PCR Products of 16S rDNA by Agarose Gel Electrophoresis. 1囚2: Black control; 3₫4:WA4-31 16S rDNA; 5:2000 DNA marker. (e) Phylogenetic Tree of Strain WA 4-31. Maximum-likelihood phylogenetic tree based on 16S rDNA gene sequences showing the positions of strain WA 4-31, the type strains of other Gordonia and representatives of some other related taxa. Only bootstrap values (expressed as percentages of 1,000 replications) greater than $50 \%$ are shown at branching points. Bar, 0.02 substitutions per nucleotide position. 

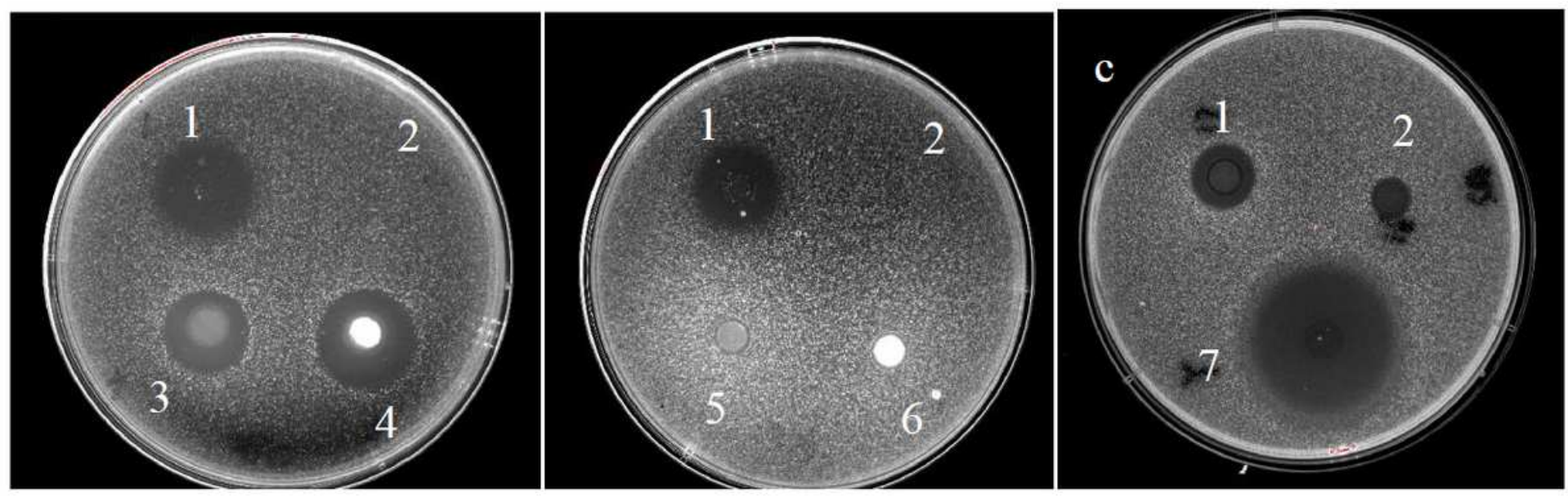

Figure 2

The antibacterial activity of different fractions against Candida albicans with Oxford Cup method (a) The 3rd and the 4th fractions had anti-Candida albicans activity, (b) while the 5th and the 6th did not, (c) The 10th fraction had stronger antibacterial activity. 1: Positive drug: Amphotericin B, $32 \mu \mathrm{g} / \mathrm{mL}$; 2: Blank control: methanol solution; 3-7: Methanol solutions with different fractions, 5mg/mL.
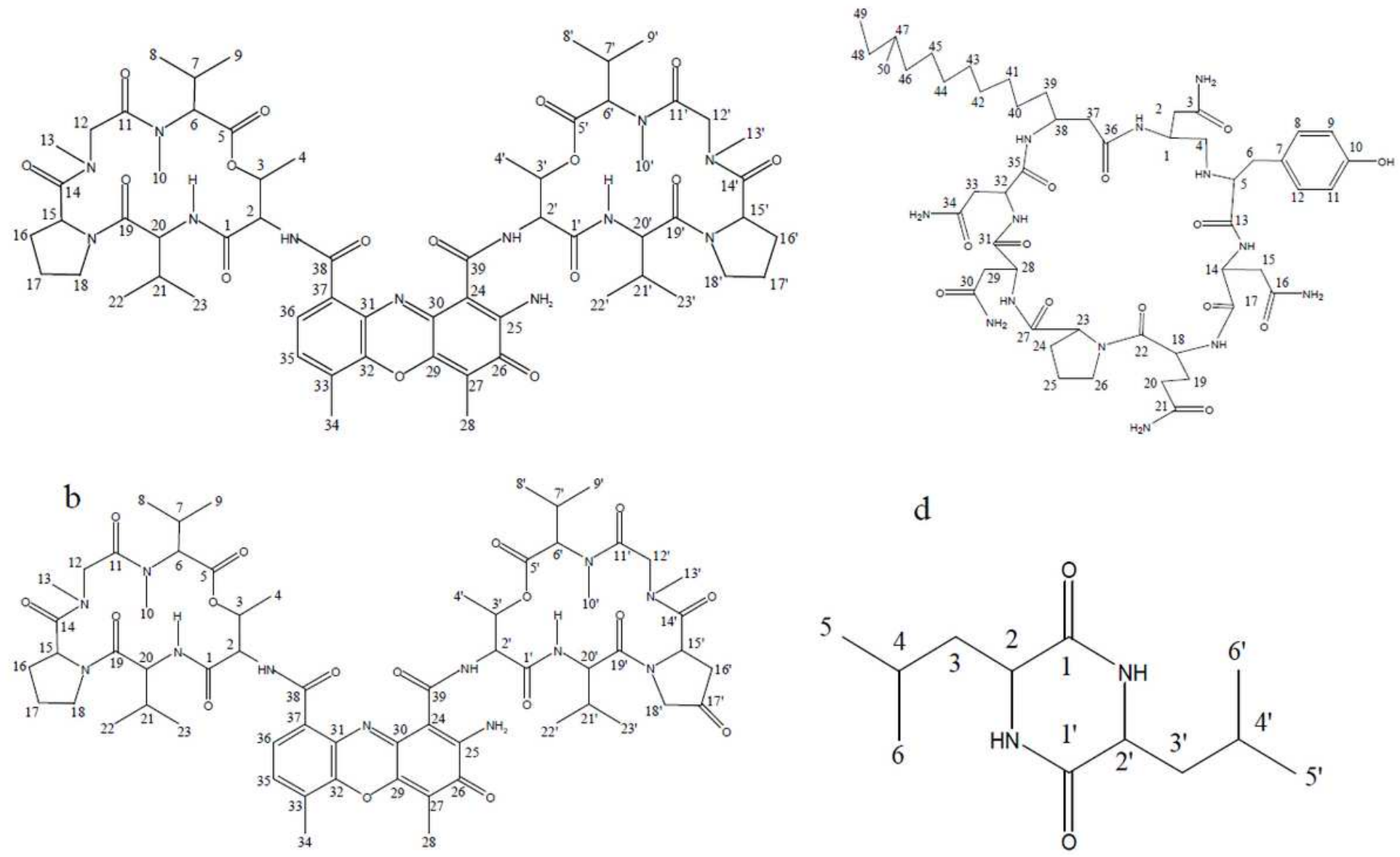

Figure 3 
Molecular Structure of compound 1-4 (a) compound 1: Actinomycin D. (b) compound 2: Actinomycin X2. (c)compound 3: Mojavensin A. (d)compound 4: cyclic (leucine-leucine) dipeptide
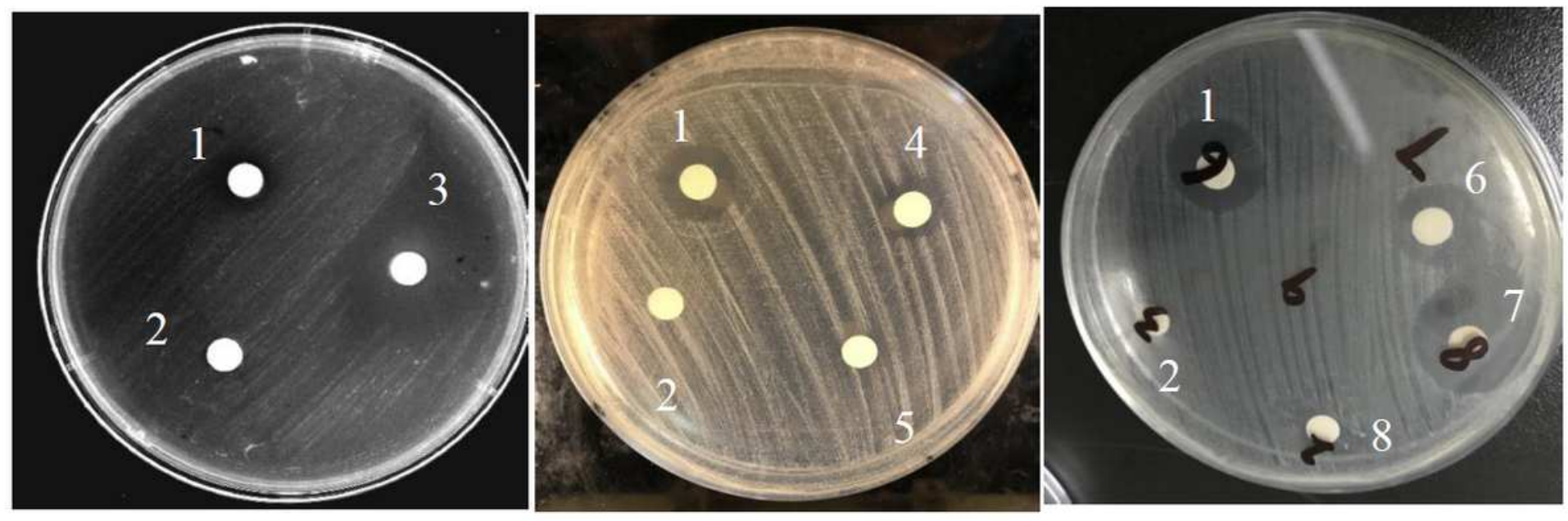

\section{Figure 4}

Activity of various samples against Candida albicans by Filter paper method 1: Positive drug:

Amphotericin B, $32 \mu \mathrm{g} / \mathrm{mL}$; 2: Blank control: methanol solution; 3:the tenth fraction dissolved in methanol, $1 \mathrm{mg} / \mathrm{mL}$; 4: Mojavensin A dipeptide dissolved in methanol, $512 \mu \mathrm{g} / \mathrm{mL}$; 5 : Cyclic (leucine-leucine) dipeptide dissolved in methanol, $512 \mu \mathrm{g} / \mathrm{mL}$; 6: Mojavensin A: cyclic (leucine-leucine) dipeptide =2: 1; 7 : Mojavensin A: cyclic (leucine-leucine) dipeptide =1: 1; 8: Mojavensin A: cyclic (leucine-leucine) dipeptide $=1: 2$. 

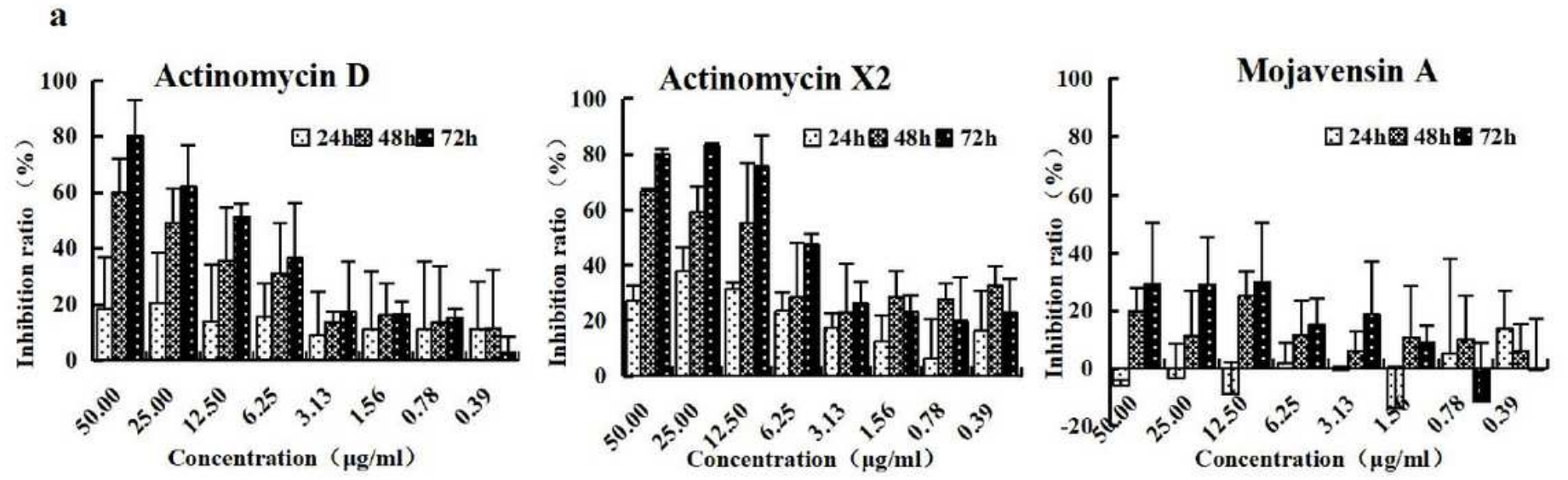

b
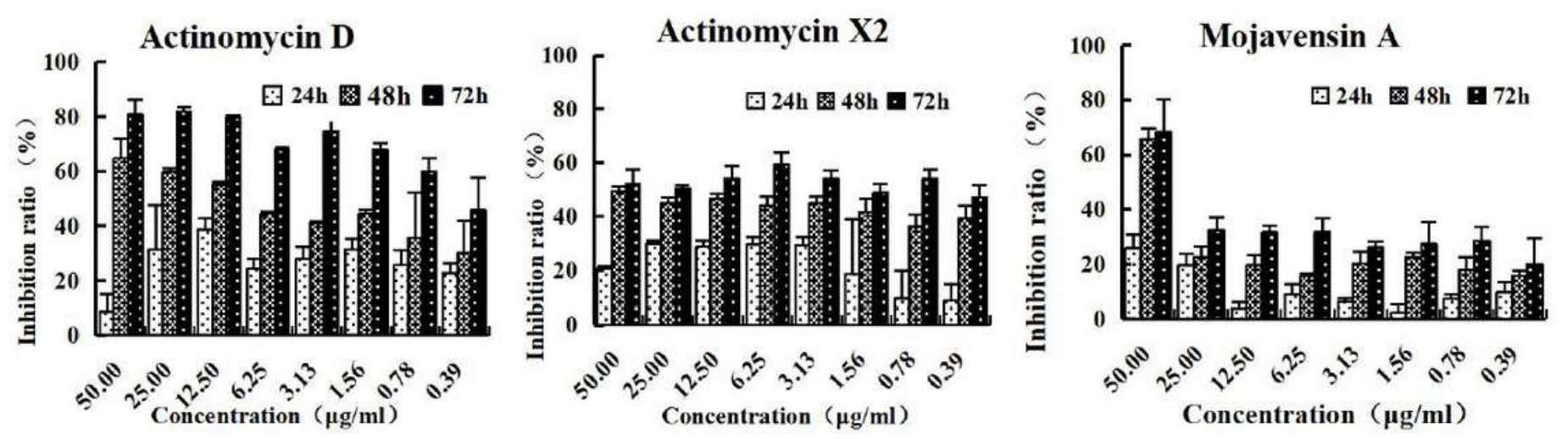

Figure 5

The cytotoxicity (MTT ASSAY) results of compounds on HepG-2cells (a) and CNE-2 cells(b) at the different concentrations for 24-72 $\mathrm{h}$

\section{Supplementary Files}

This is a list of supplementary files associated with this preprint. Click to download.

- Table1.tif

- Table3.tif

- Table2.tif

- Table4.tif

- SupplementaryFigures.docx

- SupplementaryTables.docx 